\title{
Transport of terpenes through composite PDMS/PAN solvent resistant nanofiltration membranes
}

\author{
M. H. Abdellaha, C. A. Scholes ${ }^{\text {a }}$, B. D. Freeman' ${ }^{\text {, L. Liü }}$, S. E. Kentish* \\ a Department of Chemical Engineering, The University of Melbourne, Parkville, Melbourne, \\ 3010, Australia \\ ${ }^{b}$ Department of Chemical Engineering, The University of Texas at Austin, Austin, Texas \\ 78712, United States
}

\begin{abstract}
Terpenes such as $d$-limonene, $\alpha$-pinene and p-cymene are considered green solvents that have no harmful effects on human health and the environment. These solvents represent promising alternatives for many recently-classified harmful solvents such as n-hexane, the typical solvent used for the extraction of vegetable oils. Although terpenes show high solvation power for the different oil constituents, their recovery by conventional evaporation stands as a barrier for their large-scale utilisation as they have significant higher boiling points than $n$-hexane. In this work, the transport of terpenes through a composite PDMS/PAN membrane is investigated at different experimental conditions. A nonlinear increase in the solvent flux was observed with increasing transmembrane pressure which could be explained by the solution-diffusion model in a highly swollen membrane. The highest fluxes were observed with d-limonene followed by $\mathrm{p}$-cymene then $\alpha$-pinene. The sorption equilibria and diffusion coefficient of the terpenes in free-standing PDMS films were also studied and this data used to successfully model the permeation data. The performance of the PDMS/PAN membranes was stable after storage in the solvents for one year. The results obtained from this study indicate potential utilisation of solvent resistant nanofiltration for the recovery of terpenes with minimal energy consumption.
\end{abstract}

Keywords: Terpenes; PDMS; solvent resistant nanofiltration; green solvents

* Corresponding author: sandraek@unimelb.edu.au 


\section{Introduction}

Solvent resistant nanofiltration (SRNF) is a versatile technology that represents a promising alternative to conventional separation techniques. Recently, the technology has been proposed as a replacement for energy-intensive separation processes such as distillation, evaporation and liquidliquid extraction[1,2]. The application of solvent resistant nanofiltration in the food industry, particularly the vegetable oil industry, is a growing field of research $[3,4]$. In recent years, the focus has been directed at the recovery of solvent, typically hexane from the vegetable oil/hexane micella [3-8], as well as degumming [9-13] and deacidification [14,15] of the crude oils either undiluted or diluted with common solvents. The outcomes from these studies have demonstrated that membrane technology in the vegetable oil processing can solve many of the problems associated with current technology.

$\mathrm{N}$-hexane is the typical solvent used for the extraction of crude vegetable oils from their oilseeds but is now recognised as carcinogenic [16,17]. Green solvents, known as terpenes represent promising alternatives to $n$-hexane [18]. These solvents, extracted from natural products such as citrus peels and rosemary leaves, include $\alpha$-pinene, $\mathrm{d}$-limonene and p-cymene. Compared with $\mathrm{n}$-hexane, terpenes are safer for human health as well as the environment and are already used in the food and pharmaceutical industries [19-21]. Numerous studies have been conducted to investigate the affinity and selectivity of these solvents to the different constituents of edible oils [22-27]. The results obtained reveal that terpenes can dissolve oil constituents as efficiently as n-hexane. However, they require more energy during recovery using conventional evaporation than $n$-hexane, due to high boiling points and latent heat of vaporization [22]. Solvent resistant nanofiltration is considered a feasible alternative solvent recovery process [27]. Compared with evaporation, solvent resistant nanofiltration consumes less energy as the separation takes place at mild temperature, as well as ensuring better product quality by avoiding the thermal degradation of heat sensitive natural nutrients 
$[11,28]$. Shifting this technology from lab-scale study to industrial scale requires understanding the transport of terpenes and their oil solutions through solvent resistant nanofiltration membranes.

Over the last two decades, a range of models has been developed to describe the transport of different species through SRNF membranes. These models are extended from aqueous systems with some modifications accounting for solvent-solute-membrane interactions. Most originate either from the solution-diffusion approach, where the transport is controlled by diffusive effects, or the pore flow approach where the transport is controlled by viscous-convective effects [29-34]. Some models also account for both diffusive and viscous flow effects $[35,36]$.

Based on the solution-diffusion mechanism, Bhanushali et al.[29] developed a semi-empirical model for predicting the flux $(J)$ of pure solvents through polymeric membranes (Eq. 1)

$$
J \alpha\left(\frac{V_{m}}{\mu}\right)\left(\frac{1}{\emptyset^{n} \gamma_{s v}}\right)
$$

The author introduced the solvent viscosity $(\mu)$ and molar volume $\left(V_{m}\right)$ as solvent parameters, while the solid-vapour surface tension $\left(\gamma_{s v}\right)$ and the interaction parameter $(\varnothing)$ described the membrane performance. The empirical exponent $(n)$ is introduced to obtain the best fit to the experimental data. The model was verified with different classes of solvents and different types of membranes and showed good agreement with the experimental data. Geens et al. [30] simplified this model, using the difference in surface tension between the membrane and solvent as a single parameter expressing their interaction (Eq. 2)

$$
J \alpha\left(\frac{V_{m}}{\mu \Delta \gamma}\right)
$$

Where $V_{m}$ is the solvent molar volume, $\mu$ is the solvent viscosity and $\Delta \gamma$ is the surface tension difference between the membrane material and the solvent.

Silva et al. [34]concluded that both a pore flow model and solution diffusion model could be used to predict the permeation of pure solvents through a polyimide SRNF membrane. Darvishmanesh et 
al.[35] developed a semi-empirical model based on the solution-diffusion with imperfections model which accounts for both diffusive and viscous flow. Equation 3 was used to predict the volumetric flux $(U)$ of a broad range of solvents through SRNF membranes (polymeric and ceramic):

$$
J=\frac{a_{o} \alpha}{\mu \exp (1-\beta)}(\Delta p-\Delta \pi)+\frac{b_{o}}{\mu \exp (1-\beta)} \Delta p
$$

where $\alpha$ is the non-dimensional polarity coefficient, $\beta$ is the ratio of the surface tension of the solvent and the membrane, $\Delta p$ is the transmembrane pressure and $\Delta \pi$ is the osmotic pressure difference. The parameters $a_{o}$ and $b_{o}$ are specific diffusivity and permeability values, determined during the modelling. Starting with the Hagen-Poiseuille equation, Marchetti et al.[31] derived a model to describe the permeation of pure solvents and organic solvent mixtures through ceramic NF and UF membranes. The author introduced new correction parameters accounting for membranesolvent interactions. These parameters are the capillary pressure term, the dipole and the steric terms which are function of the membrane pore size. In a further paper, the same group[37] concluded that solution diffusion-based models give better predictions of the permeation through glassy polyimide and rubbery membranes while pore flow models showed better predictions of the permeation through the high permeability poly[1-(trimethylsilyl)-1-propyne] (PTMSP) and poly[4-methyl-2pentyne] (PMP) polymers. Although, these models gave good agreement with the experimental results, they failed to predict the nonlinear flux behaviour obtained in SRNF membranes when experiencing a high degree of swelling.

The aim of this investigation is to understand the transport of terpenes through polymeric SRNF membranes where a high degree of swelling occurs. The solution diffusion model, as originally developed by Paul and Ebra-Lima over forty years ago [38] is successfully used to describe the data even under conditions of high swelling within the PDMS/PAN composite membrane. 


\section{Theory and model development}

The model we use here is based on combining the solution-diffusion mechanism with the FloryHuggins model for penetrant solubility in a rubbery polymer. The solution-diffusion mechanism assumes that the transport of a penetrant through the membrane is due to the decrease in chemical potential of the component from the feed to the permeate interfaces. Further, it assumes that the pressure inside the membrane is uniformly distributed and equal to the feed pressure. At the permeate interface, there is a sudden drop in the pressure from the feed pressure to the permeate pressure[39]. For an incompressible system, the chemical potential of a penetrant $(s)$ can be expressed in terms of the activity $\left(a_{s}\right)$, the partial molar volume of the penetrant inside the membrane $\left(V_{s}\right)$ and the feed pressure $\left(P_{f}\right)$ as follows[39]:

$$
\mu_{s}=\mu_{s}^{o}+R T \ln a_{s}+V_{s}\left(P_{f}-P_{r}\right)
$$

Where $\mu_{i}^{o}$ is the standard chemical potential at a reference pressure $P_{r}$. The chemical potential of the penetrants at the interface between a membrane and a free solution must be equal (i.e. $\mu_{s}=\mu_{s}^{m}$ ) and thus the conditions on the feed side of the membrane can be expressed as Eq. 5, if the permeate pressure $\left(P_{p}\right)$ is used as the reference pressure:

$$
R T \ln a_{s, f}+V_{s}\left(P_{f}-P_{p}\right)=R T \ln a_{s, f}^{m}+\bar{V}_{s}\left(P_{f}^{m}-P_{p}\right)
$$

Where $\bar{V}_{S}$ is the partial molar volume of the penetrant inside the membrane. According to the solution-diffusion mechanism, the pressure in the feed solution is equal to that at the feed side of the membrane $\left(P_{f}^{m}=P_{f}\right)$ and if it is assumed that there is no volume change on mixing then $V_{s}=\bar{V}_{s}$, which is typically taken to be a good assumption. For a pure solvent $a_{s, f}=1$ and hence at the feed side $a_{s, f}^{m}=1$. Similarly, equating the chemical potential of the penetrant at the permeate interface,

$$
R T \ln a_{s, p}+V_{s}\left(P_{p}-P_{p}\right)=R T \ln a_{s, p}^{m}+\bar{V}_{s}\left(P_{p}^{m}-P_{p}\right)
$$


In accordance with the solution-diffusion mechanism, the pressure inside the membrane at the permeate side $\left(P_{p}^{m}\right)$ is equal to the feed pressure $\left(P_{f}\right)$. Rearrangement of Eq. 6 gives the solvent activity inside the membrane at the permeate interface as a function of the feed pressure as follows[40]:

$$
a_{s, p}^{m}=\exp \left[\frac{-\bar{V}_{s}}{R T}\left(P_{f}-P_{p}\right)\right]
$$

Eq. 7 shows that the activity of the solvent inside the membrane at the permeate side decreases exponentially with increases in feed pressure. This effect becomes more significant at high pressure and with high partial molar volume penetrants[38].

The ratio of the solvent activity inside the membrane at both interfaces can be expressed as follows:

$$
\frac{a_{s, p}^{m}}{a_{s, f}^{m}}=\exp \left[\frac{-V_{s}}{R T}(\Delta P)\right]
$$

Paul and Ebra Lima [38] used Fick's Law to develop an expression for the solvent flux $\left(U_{s}\right)$ as a function of the difference in the volume fractions of the solvent inside the membrane at its interfaces (Equation 10). This equation assumes that the diffusion coefficient $\left(D_{S}\right)$ is independent of concentration and that there is no volume change upon mixing.

$$
J_{s}=\frac{D_{s}}{l_{d} v_{p o, f}^{2 / 3}}\left(v_{s, f}^{m}-v_{s, p}^{m}\right)
$$

Here, $l_{d}$ is the dry membrane thickness, $v_{p o, f}$ is the volume fraction of polymer at the feed interface. $v_{s, f}^{m}$ and $v_{s, p}^{m}$ are the volume fraction of the penetrant inside the membrane at the feed and permeate interfaces. 
According to the Flory-Huggins model, the activity of the penetrant $\left(a_{s}\right)$ is related to the equilibrium volume fraction of the penetrant inside the polymer $\left(v_{s}^{m}\right)$ through an interaction parameter $(\chi)$ as shown in Eq. 10[41]:

$$
\ln a_{s}^{m}=\ln v_{s}^{m}+\left(1-\frac{V_{s}}{V_{p o}}\right)\left(1-v_{s}^{m}\right)+\chi\left(1-v_{s}^{m}\right)^{2}
$$

where $V_{S}$ is the penetrant molar volume and $V_{p o}$ is the penetrant-free polymer molar volume. Due to the much larger molar volume of the polymer compared with that of the penetrant, the term $\frac{V_{S}}{V_{p o}}$ in Eq. (10) can usually be neglected. Small values $(\chi<0.5)$, indicate a high affinity between the penetrant and the polymer with expected polymer solvation, unless crosslinking is used [29]. On the other hand, large values $(\chi>2)$, refer to limited penetrant-membrane interaction with subsequent limited solubility and permeability. For intermediate values $(2>\chi>0.5)$, a strong penetrantpolymer interaction exists, thus high solubility is expected.

Accordingly, the ratio between the penetrant activity inside the membrane at the feed and permeate sides can be expressed as:

$$
\frac{a_{s, p}^{m}}{a_{s, f}^{m}}=\frac{v_{s, p}^{m} \exp \left[1-v_{s, p}^{m}+\chi\left(1-v_{s, p}^{m}\right)^{2}\right]}{v_{s, f}^{m} \exp \left[1-v_{s, f}^{m}+\chi\left(1-v_{s, f}^{m}\right)^{2}\right]}
$$

Substituting $v_{s}=V_{s} \times \mathrm{C}_{\mathrm{s}}$ in Eqs. 9 and 11 gives,

$$
\begin{gathered}
\frac{a_{s, p}^{m}}{a_{s, f}^{m}}=\frac{C_{s, p}^{m} V_{s} \exp \left[1-C_{s, p}^{m} V_{s}+\chi\left(1-C_{s, p}^{m} V_{s}\right)^{2}\right]}{C_{s, f}^{m} V_{s} \exp \left[1-C_{s, f}^{m} V_{s}+\chi\left(1-C_{s, f}^{m} V_{s}\right)^{2}\right]} \\
J_{s}=\frac{D_{s} V_{s}}{l_{d}\left(1-\bar{V}_{s} C_{s, f}^{m}\right)^{2 / 3}}\left(\mathrm{C}_{s, f}^{m}-\mathrm{C}_{s, p}^{m}\right)
\end{gathered}
$$

Where $\mathrm{C}_{\mathrm{s}}$ is the molar concentration of the penetrant inside the membrane (mole $/ \mathrm{m}^{3}$ ). 
Rearrangement of Eq. 12 and combining with Eqs. 8 and 13, the pure solvent flux can be expressed in terms of the transmembrane pressure as follows:

$$
J_{s}=\frac{D_{s} V_{s} C_{s, f}}{l_{d}\left(1-V_{s} C_{s, f}^{m}\right)^{2 / 3}}\left[1-\exp \left\{V_{s}\left(C_{s, p}^{m}-C_{s, f}^{m}\right)+\chi\left[\left(1-C_{s, f}^{m} V_{s}\right)^{2}-\left(1-C_{s, p}^{m} V_{s}\right)^{2}\right]\right\} \times \exp \left[\frac{-V_{s}}{R T}(\Delta P)\right]\right]
$$

\section{Material and methods}

\subsection{Materials}

Analytical grade p-cymene (purity $99 \%$ ), d-limonene (purity $97 \%$ ) and $\alpha$-pinene (purity $98 \%$ ) were purchased from Sigma-Aldrich. PDMS pre-polymer (KE106) and the curing agent CAT-RG were supplied by Shin-Etsu Chemical, Japan. N-heptane and $\mathrm{n}$-hexane were obtained from ChemSupply. All chemicals were used as received without further purification. A polyacrylonitrile (PAN) support membrane with MWCO 20kDa was obtained from $\mathrm{AMI}^{\circledR}$, USA. The membrane was supplied in a dry condition and was used without further treatment.

\subsection{Preparation and characterization PDMS/PAN composite membrane}

Composite PDMS/PAN membranes were prepared by the solution casting method to produce a uniform film thickness. A 7 wt. \% PDMS solution in $n$-heptane was prepared by dissolving the prepolymer and the crosslinker at a ratio of 2:1 (w/w). N-heptane was selected due to its lower vapour pressure compared with $n$-hexane, giving more control during the film casting. To minimise the potential for defect formation in the cast film and facilitate the casting process, the polymer solution was pre-crosslinked to increase its viscosity. The pre-crosslinking was accomplished by heating the mixture in a water bath at $60^{\circ} \mathrm{C}$ for $3 \mathrm{hrs}$ under vigorous stirring. The mixture was then quenched with ice water to stop the reaction and avoid gelation of the polymer. The mixture was sonicated for 30 minutes to remove trapped air bubbles. The PAN support membrane was washed and immersed in distilled water for $1 \mathrm{hr}$ to fill the pores with water to minimise pore intrusion during film casting. The PAN support was taped onto a clean glass plate and the top surface was wiped gently with tissue paper 
to get rid of any water droplets. A $500 \mu \mathrm{m}$ wet thickness film was cast on the support membrane using a casting blade. The membrane was left for $1 \mathrm{hr}$ at ambient conditions to evaporate the solvent. The membrane was then placed under vacuum for another $1 \mathrm{hr}$ before being thermally cured in a vacuum oven at $70^{\circ} \mathrm{C}$ for $2 \mathrm{hrs}$ followed by additional $2 \mathrm{hrs}$ at $120^{\circ} \mathrm{C}$ to complete the crosslinking reaction. The formed membrane was cut into coupons of a size equal to the membrane cell and stored under vacuum until use.

The quality of the cast film was evaluated by measuring the membrane selectivity to $\mathrm{CO}_{2} / \mathrm{N}_{2}$. The permeability of $\mathrm{CO}_{2}\left(P_{\mathrm{CO}_{2}}\right)$ and $\mathrm{N}_{2}\left(P_{\mathrm{N}_{2}}\right)$ through the membrane were measured using a previously established procedure and used to calculate the membrane selectivity $\left(\alpha_{\mathrm{CO}_{2} / \mathrm{N}_{2}}\right)$ [42,43]. The selectivity $\left(\alpha_{\mathrm{CO}_{2} / \mathrm{N}_{2}}\right)$ of the composite membranes was $9.3 \pm 0.1$, which agrees with values reported in the literature $[44,45]$.

The thickness of the PDMS film was measured from cross-sectional images taken by a Scanning Electron Microscope (FEI Quanta 200 ESEM FEG) and was $23 \pm 3 \mu m$. The SEM image (Fig. 1) shows a dense PDMS film on a porous support of PAN with no observed pore intrusion.

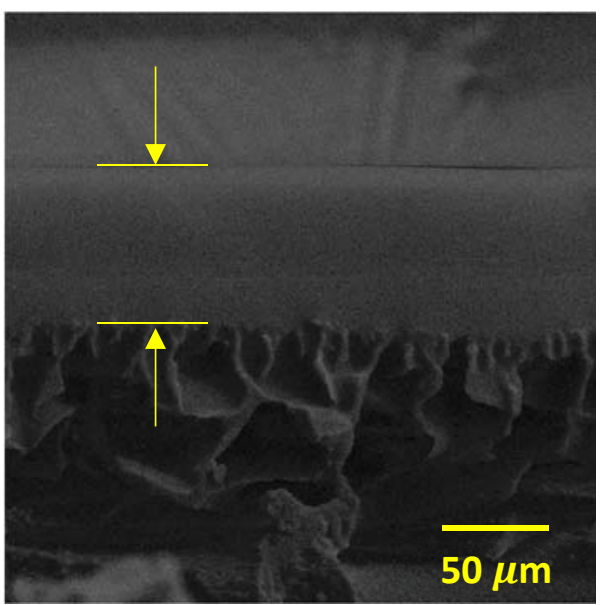

Figure 1. Cross-sectional SEM image of the composite PDMS/PAN membrane

Contact angle measurements using a FTA200 Tensiometer gave values of 22 degrees for the PAN support and 115 degrees for the PDMS coated membrane (see Supplementary Information), consistent with previously reported results for these materials $[46,47]$. 
The root-mean square roughness (RMS) values of the PAN support and the PDMS coated membrane were measured using an Atomic Force Microscope (Cypher AFM, Asylum, USA) as 9.3 and $1.2 \mathrm{~nm}$ respectively (see Supplementary Information), indicating the good quality of the casting process.

\subsection{Preparation of free-standing thick PDMS films}

Thick PDMS films for sorption analysis were prepared from 50 wt. \% PDMS solution in n-heptane with a polymer to crosslinker ratio of 2:1 $(\mathrm{w} / \mathrm{w})$. The mixture was homogenised by magnetic stirring for one hour. To obtain a homogeneous film without defects, the polymer mixture was sonicated for 30 minutes in a cooled water bath. The polymer was poured onto a non-stick transparency film (Phaser 740, Tektronix) fixed between a glass plate and a frame. The film was left for one hour to evaporate the solvent then for 60 minutes under vacuum. The film was thermally cured under the same conditions used for the preparation of the composite PDMS/PAN membrane. The PDMS film was washed with $\mathrm{n}$-hexane for 3 days under stirring to remove any unreacted crosslinker or polymer. The hexane was replaced every 24 hours to avoid contamination of the PDMS films with any leached materials. Finally, the film was dried under vacuum at $25^{\circ} \mathrm{C}$ for two days. The PDMS film thickness was measured by a digital micrometre (Mitutoyo) and had an average value of $1.97 \pm 0.04 \mathrm{~mm}$. The density of these PDMS films at $25{ }^{\circ} \mathrm{C}$ was $1.022 \pm 0.005 \mathrm{~g} / \mathrm{cm}^{3}$, which was determined from the mass measurements of different samples in air and in distilled water. This value is consistent with other literature reports $[48,49]$. The film was stored under vacuum at ambient temperature until use.

\subsection{Sorption Kinetics and Equilibria}

The sorption kinetics of $p$-cymene, $d$-limonene and $\alpha$-pinene in free-standing PDMS films were studied by a gravimetric method at atmospheric pressure[45]. PDMS samples were immersed in the different solvents at $25^{\circ} \mathrm{C}$. After a certain time, the films were removed, wiped clean with a tissue paper and weighed. Each measurement was done within 30 seconds to minimise any error due to solvent evaporation. The process continued until a constant mass of PDMS samples was reached. After reaching equilibrium, the degree of swelling (\% SD) of the films was calculated according to Eq. (15). 


$$
\% S D=\frac{m_{e q}-m_{\text {initial }}}{m_{\text {initial }}} \times 100
$$

Where $m_{e q}$ and $m_{\text {initial }}$ are the equilibrium and initial masses of the PDMS film, respectively.

These swelling kinetics could not be conducted for hexane as the greater volatility of this solvent led to significant error during the weighing step.

\subsection{Permeation experiments}

The permeation experiments were conducted in a cross-flow membrane cell (Sterlitech-CF042) with a membrane active area of $42 \mathrm{~cm}^{2}$ (Fig. 2). The cell has a flow channel of $9.2 \mathrm{~cm}$ length, $4.6 \mathrm{~cm}$ width and $2.3 \mathrm{~mm}$ depth. The solvent was fed to the membrane cell by a variable speed positive displacement pump (Hydra cell P200). A pulsation dampener was mounted on the discharge line of the pump to minimise flow and pressure fluctuations. The temperature of the feed was controlled by passing the feed through coiled piping placed in a temperature-controlled water bath. The pressure on the feed side of the membrane was controlled by a needle valve mounted on the retentate line, with pressure gauges (Floyd) recording both the feed and retentate sides. After reaching stable conditions, the permeate was collected and weighed on a digital balance (Ohaus) at intervals of 5 min. The balance was connected to a PC to record the data using TWedge data acquisition software.

For each of the solvents, a new membrane coupon was used. These coupons were cut from the same membrane sheet to minimise the variability in results due to casting procedures. Before each experiment, the membrane coupon was washed and compacted at 30 bar for $3 \mathrm{hrs}$ using $\mathrm{n}$-hexane followed by the solvent to be permeated for an additional $3 \mathrm{hrs}$. The steady state permeate flux was calculated according to Eq. (16).

$$
J_{p}=\frac{m_{p}}{t \times A} \quad\left(k g / m^{2} \cdot h r\right)
$$

Where $m_{p}(\mathrm{~kg})$ is the mass of the permeate collected at time $t(\mathrm{hr})$ and $A$ is the membrane active area $\left(42 \times 10^{-4} \mathrm{~m}^{2}\right)$. The viscosity of the solvents was measured using a calibrated Ubbelhode viscometer while the density was determined using a 50-ml pycnometer. 


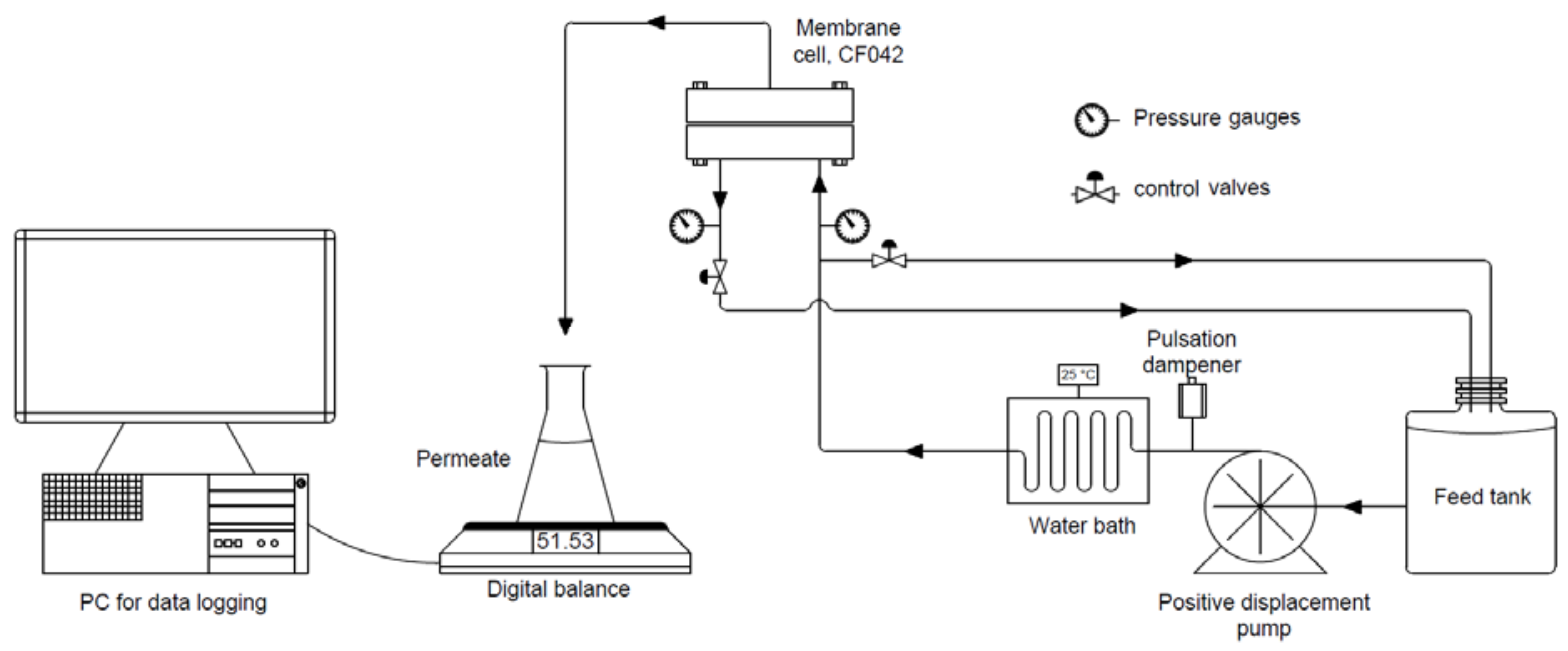

Figure 2. Schematic representation of the experimental apparatus used in the filtration study

\section{Results and discussion}

\subsection{Sorption Kinetics and Equilibria}

Fig. 3 depicts the sorption kinetics of terpenes in free-standing PDMS films at $25^{\circ} \mathrm{C}$. A rapid sorption initially occurred which was nearly linear with the square root of time, consistent with Fickian diffusion behaviour. 


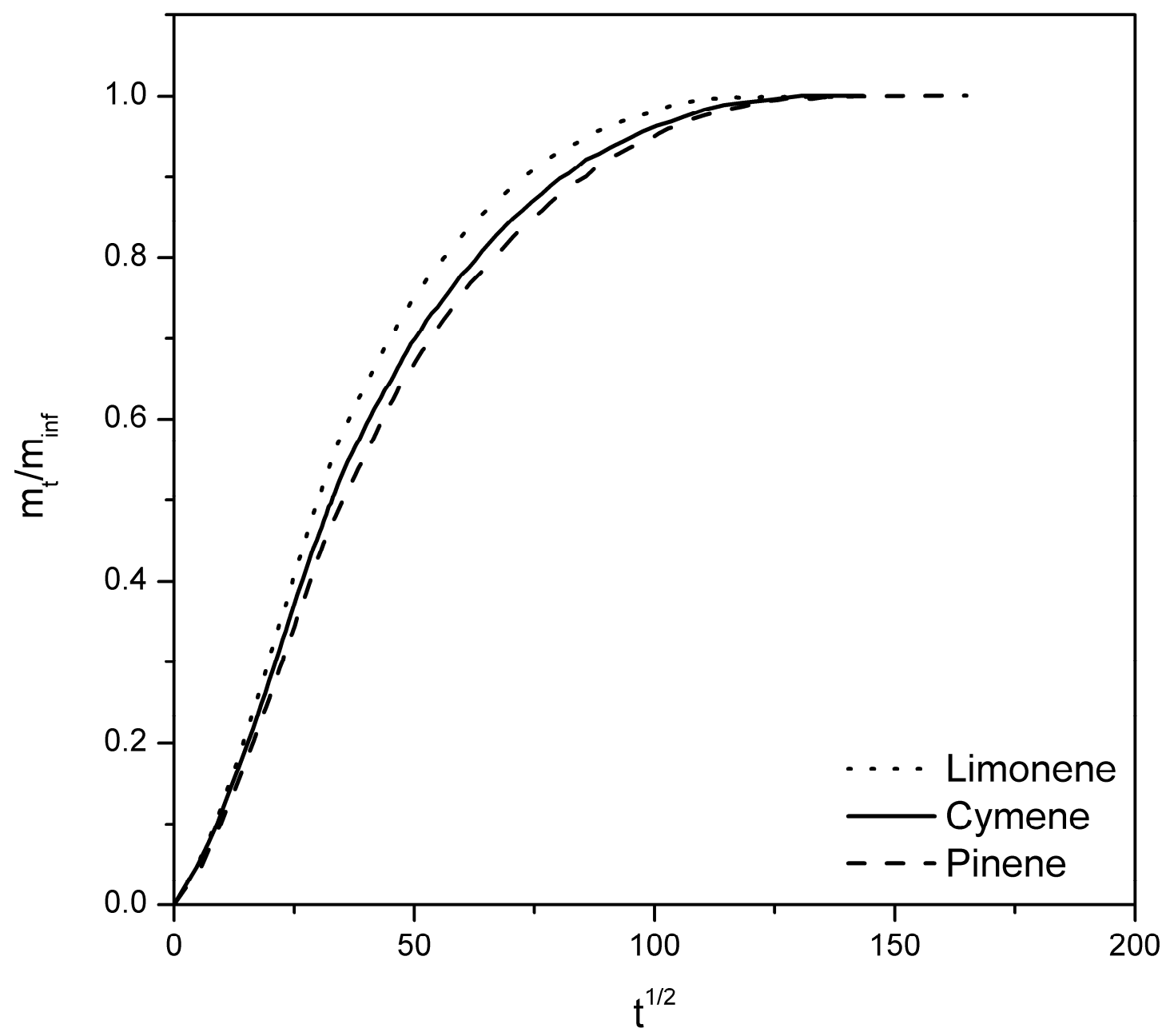

Figure 3. Sorption kinetics of terpenes in PDMS films at $25 \mathrm{C}$, where the film mass has been normalised to the equilibrium uptake.

The sorption kinetics of the terpenes in the PDMS films were used to estimate their diffusion coefficients via Eq.(17) developed by Crank [50]which express the mass uptake of a penetrant in a polymer film at time $t$ :

$$
\frac{m_{t}}{m_{\infty}}=1-\sum_{n=0}^{\infty} \frac{1}{(2 n+1)^{2} \pi^{2}} \exp \left[-\frac{D_{i}(2 n+1)^{2} \pi^{2} t}{l^{2}}\right]
$$

where $m_{t}$ and $m_{\infty}$ are the mass absorbed of penetrant $i$ by the polymer at a time $t$ and at the equilibrium, $l$ is the film thickness, $D_{i}$ is the effective penetrant diffusion coefficient through the 
polymer film. MATLAB ${ }^{\circledR}$ R2014b was used as the computational software to fit Eq. (17) to the experimental data with the diffusion coefficient $\left(D_{i}\right)$ is the fitting parameter. The estimated diffusion coefficients of $d$-limonene, $\alpha$-pinene and p-cymene are shown in Table 1.

Table 1. The estimated diffusion coefficients of $d$-limonene, $\alpha$-pinene and $\rho$-cymene in PDMS films at $25^{\circ} \mathrm{C}$ according to Eq. 17

\begin{tabular}{|c|c|c|c|}
\hline & d-limonene & p-cymene & $\alpha$-pinene \\
\hline$D \times 10^{-10}\left(\mathrm{~m}^{2} / \mathrm{s}\right)$ & $1.07 \pm 0.04$ & $0.97 \pm 0.04$ & $0.65 \pm 0.04$ \\
\hline$\mu(c P)$ & $0.83 \pm 0.01$ & $0.77 \pm 0.01$ & $1.26 \pm 0.01$ \\
\hline$\% S D$ & $277 \pm 6$ & $257 \pm 5$ & $314 \pm 6$ \\
\hline$V\left(\mathrm{~cm}^{3} / \mathrm{mol}\right)$ & 163 & 158 & 161 \\
\hline
\end{tabular}

The diffusivity of a penetrant in the polymer will depend upon its molar volume and viscosity and the degree of swelling induced by the penetrant (\%SD) $[6,51]$. In the present case, the high viscosity of $\alpha$-pinene results in it having the lowest diffusion coefficient, while the greater swelling induced by $d$ limonene results in the greatest diffusivity.

The degree of swelling (SD) was converted to the solvent volume fraction by the following equation,

$$
v_{s}^{m}=\frac{\frac{S D}{\rho_{s}}}{\frac{S D}{\rho_{s}}+\frac{1}{\rho_{p o}}}
$$

where $\rho_{s}$ and $\rho_{p o}$ are the solvent and the polymer density, respectively. This data was then fitted to Equation 10 to provide the Flory-Huggins interaction parameter (Table 2). The highest degree of swelling was found for $\alpha$-pinene, followed by $d$-limonene and then $\mathrm{p}$-cymene. These trends reflect the cohesive energy of the three solvents, as shown by the Hildebrand solubility parameter $\left(\delta_{T}^{2}=\delta_{d}^{2}+\right.$ 
$\delta_{p}^{2}+\delta_{h}^{2}$ ), where similar values to PDMS indicate strong interaction [18]. Increasing the temperature from 25 to $40^{\circ} \mathrm{C}$ had no effect on the extent of swelling.

Table 2. Solubility parameters, equilibrium volume fraction and interaction parameter Chi between PDMS and terpenes, hexane and canola oil estimated from the Flory-Huggins model and the solubility parameter approach

\begin{tabular}{|c|c|c|c|c|c|c|c|}
\hline & \multicolumn{4}{|c|}{ Hansen Solubility Parameters $\left(\mathbf{M P a}^{1 / 2}\right)$} & \multirow[t]{2}{*}{ SD (\%) } & \multirow{2}{*}{$v_{i}^{m}\left(\frac{c m^{3}}{c m^{3}}\right)$} & \multirow{2}{*}{ 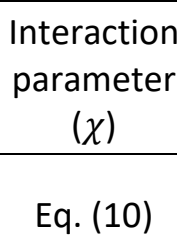 } \\
\hline & $\delta_{d}$ & $\delta_{p}$ & $\delta_{h}$ & $\delta_{t}$ & & & \\
\hline PDMS & $14.61[52]$ & $4.9[52]$ & 0 & $15.4[52]$ & ---- & ----- & ----- \\
\hline n-hexane & $14.9[52]$ & 0 & 0 & $14.9[52]$ & $260 \pm 15$ & 0.803 & 0.577 \\
\hline$\alpha$-pinene & $17[53]$ & $1.3[53]$ & $2[53]$ & $17.2[53]$ & $313 \pm 6$ & 0.786 & 0.583 \\
\hline d-limonene & $16.7[53]$ & $2.2[53]$ & $4.9[53]$ & 17.5[53] & $277 \pm 6$ & 0.769 & 0.591 \\
\hline p-cymene & $18.5[53]$ & $2.6[53]$ & $1.9[53]$ & $18.8[53]$ & $257 \pm 5$ & 0.743 & 0.603 \\
\hline
\end{tabular}

\subsection{Pure solvent transport}

The flux of $d$-limonene, $\alpha$-pinene and p-cymene through the membrane as a function of transmembrane pressures is shown in Fig. 4.Error! Reference source not found. A non-linear increase in the solvent fluxes was observed with an increase in the transmembrane pressure. This non-linear behaviour cannot readily be explained by membrane compaction as all membranes were compacted at 30 bar prior to experiments. Rather this can simply be explained by the solution-diffusion model for a penetrant of significant molar volume permeating through a highly swollen membrane. The solutiondiffusion model assumes that the membrane pressure is constant at the feed value, whereas the downstream side is exposed to a lower pressure, usually atmospheric. 


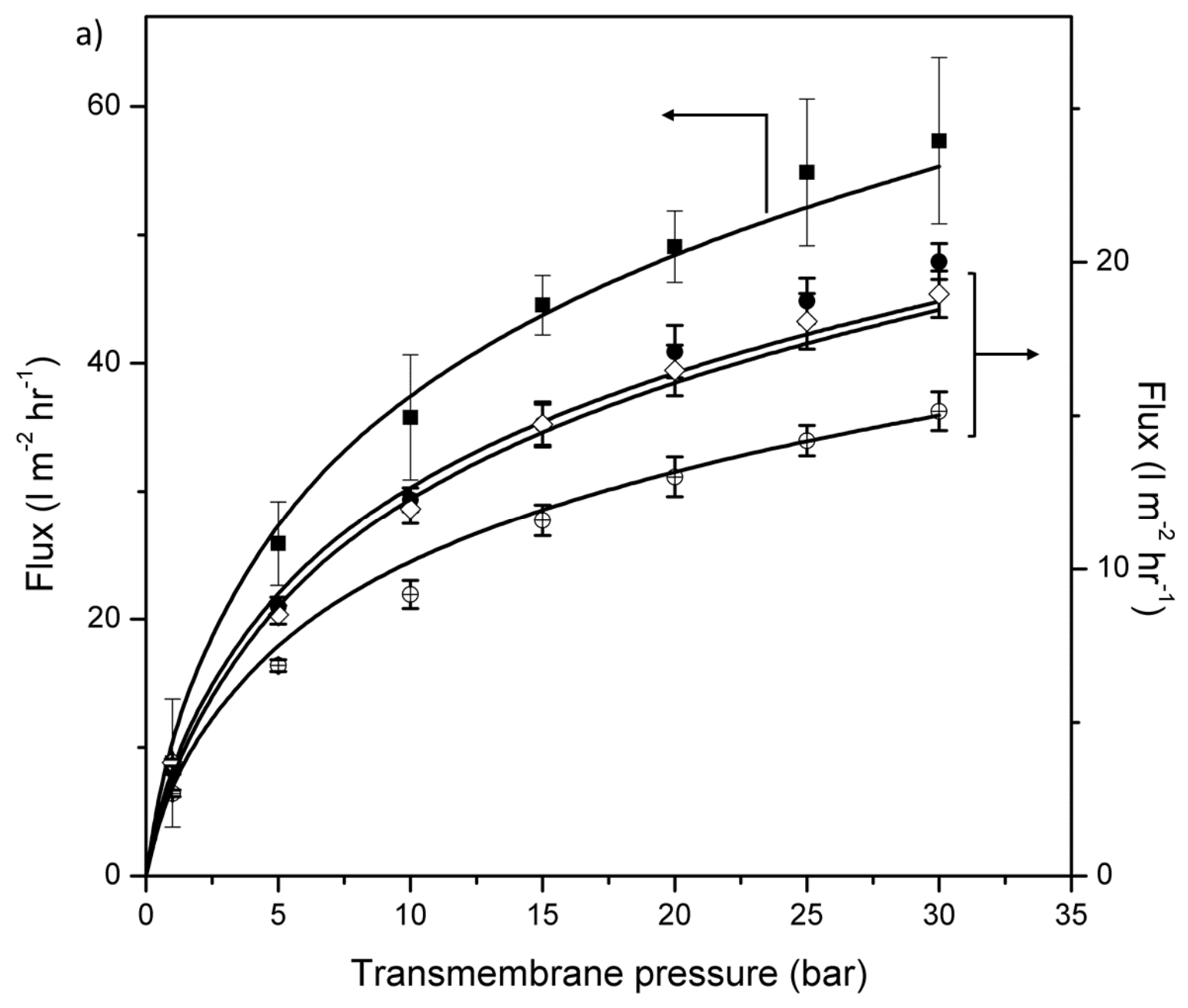




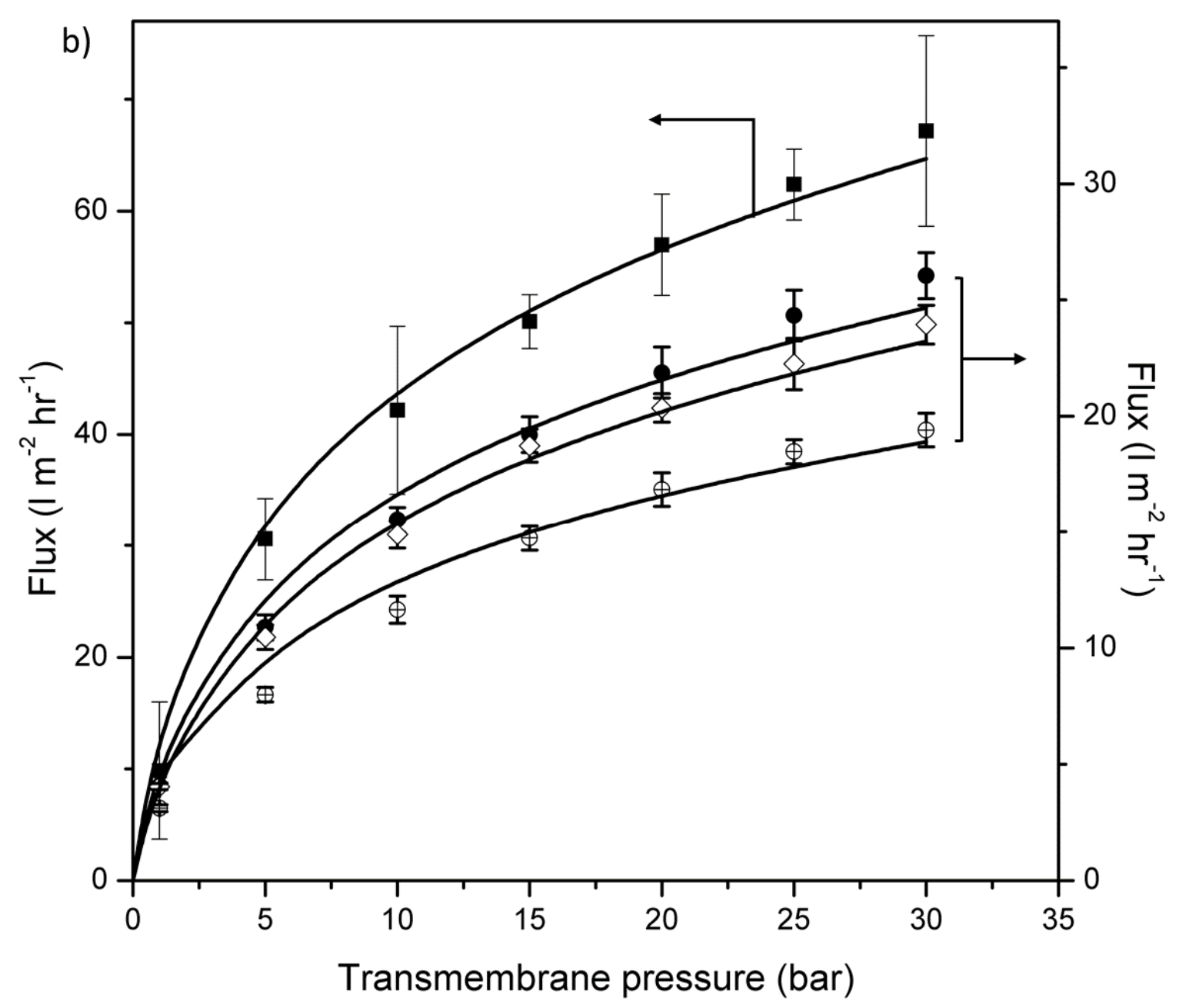

Figure 4. Pure solvent fluxes as a function of transmembrane pressure at a) $25^{\circ} \mathrm{C}$ and b) $40{ }^{\circ} \mathrm{C}$. Symbols ( $\boldsymbol{\text { hexane, }}$ Limonene, $\diamond$ Cymene and $\oplus$ Pinene) are the experimental data and solid lines represent the fitting of Eq. 14.

Consideration of chemical potentials implies that the solvent concentration falls at this downstream interface as upstream pressure increases, leading to a plateauing of the flux towards an asymptotic value at high feed pressure $[38,40,54]$. In highly swollen membranes this maximum flux is expected to be reached at lower pressures than those having a lower degree of swelling [40]. The nonlinear fluxpressure behaviour has been reported by many authours in the literature but the reasons for the behaviour are rarely attributed to this phenomenon[33,55]. Eq. 12 was solved using Matlab 2014 to estimate the solvent volume fraction values inside the membrane at the permeate interface. These values were then used to compute the pure solvent fluxes according to Eq. 14. 
The diffusion coefficients of limonene, pinene and cymene at $25^{\circ} \mathrm{C}$ were obtained from the sorption kinetics conducted at $25^{\circ} \mathrm{C}$ according to (Eq. 17), as presented in Table 1. These diffusion coefficients were used directly to calculate the solvent fluxes at $25^{\circ} \mathrm{C}$ from Eq. 14 (Fig. 4A). These model predictions shown in Fig. 4A are thus obtained without the need for any adjustable parameters. The diffusion coefficients of the pure solvents at $40^{\circ} \mathrm{C}$ and that for hexane at both temperatures (Table 3 ) were estimated by fitting the experimental flux data to Eq. 14 (Fig. 4B). A very good agreement between the experimental results and those predicted from the model can be observed. As expected, an increase in solvent diffusivity was observed with the increase in temperature due to the decrease in solvent viscosity.

Table 3. The estimated diffusion coefficients of pure solvents in PDMS.

\begin{tabular}{|c|c|c|}
\hline \multirow{2}{*}{ Solvent } & \multicolumn{2}{|c|}{ Diffusion coefficient, $D \times 10^{10}\left(\mathrm{~m}^{2} / \mathrm{s}\right)$} \\
\cline { 2 - 3 } & Estimated from Eq. 17 at $25^{\circ} \mathrm{C}$ & Estimated from Eq. 14 at $40{ }^{\circ} \mathrm{C}$ \\
\hline d-limonene & $1.07 \pm 0.04$ & $1.44 \pm 0.05$ \\
\hline p-cymene & $0.97 \pm 0.04$ & $1.24 \pm 0.03$ \\
\hline a-pinene & $0.65 \pm 0.04$ & $0.82 \pm 0.03$ \\
\hline n-hexane & $2.5 \pm 0.08^{*}$ & $3.2 \pm 0.09$ \\
\hline
\end{tabular}

* Estimated from fitting the experimental flux of $\mathrm{n}$-hexane at $25^{\circ} \mathrm{C}$ to Eq. 14 due to difficulties in measuring the sorption kinetics of $n$-hexane.

\subsection{Membrane stability}

Long-term stability is one of the main issues that limit the upscaling of SRNF processes[56]. The stability of our membrane in each solvent was investigated over a period of one year. This was accomplished by measuring the pure solvent flux through a fresh membrane, then storing the 
membrane in the solvent for one year at ambient temperature. The pure solvent flux was then measured again and compared with the initial values. Only a slight increase in the solvent fluxes $(4 \pm 1$ $\%, 3 \pm 1 \%, 3 \pm 1 \%$ and $2 \pm 1 \%$ for hexane, limonene, pinene and cymene, respectively) was observed. $\mathrm{CO}_{2} / \mathrm{N}_{2}$ selectivity of the membrane was also measured before and after storing, using previously established methods $[42,43]$. The selectivity of the fresh and the stored membrane was $9.3 \pm 0.1$ and $9.1 \pm 0.1$ respectively, again indicating that the membrane structure did not change significantly over the one year period. The mass change in free standing PDMS films stored in each solvent for one year was also recorded. Each sample was dried under vacuum for 2 days before the mass was recorded. A slight drop in mass was observed after the soaking period (1.7 to $2.4 \%$ ) which is attributed to leaching out of unreacted crosslinker and catalyst $[57,58]$. Visual inspection of the membrane showed no variation in either the texture or the colour after storage. These findings confirm the long-term stability of the PDMS membranes in these solvents 


\section{Conclusions}

In this work, the transport of terpenes through PDMS/PAN composite solvent resistant nanofiltration membrane was studied. Solvent viscosities and the degree of swelling were found to be the main parameters affecting transport of these solvents through the PDMS/PAN membrane. The highest permeate fluxes were observed with d-limonene, reflecting the greater extent of swelling induced by this penetrant and its relatively low viscosity. A nonlinear increase in the permeate flux was observed with increasing transmembrane pressure which was explained by the reversible swelling of highly swollen membranes. This behaviour was successfully described mathematically by a transport model originating from the solution-diffusion mechanism combined with the Flory-Huggins equation. This model used easily measurable parameters such as the diffusivity and Flory-Huggins interaction parameter. The composite membrane showed good stability in the different solvents over a one year period. The results obtained from this study indicate the potential to utilise solvent resistant nanofiltration to recover such green solvents from vegetable oil mixtures efficiently with minimal energy consumption.

\section{Acknowledgements}

M. H. Abdellah acknowledges The University of Melbourne for the International Postgraduate Research Scholarship. L. Liu and S.E. Kentish acknowledge funding support from the Australian Research Council (ARC) Discovery Program (DP150100977). B.D. Freeman gratefully acknowledges support from the Australian-American Fulbright Commission for the award of a U.S. Fulbright Distinguished Chair in Science, Technology, and Innovation sponsored by the Commonwealth Scientific and Industrial Research Organization (CSIRO). The assistance of the Materials Characterisation and Fabrication Platform (MCFP) at the University of Melbourne in completing the Atomic Force Microscopy analysis is also gratefully acknowledged. 


\section{References}

[1] X.Q. Cheng, Y.L. Zhang, Z.X. Wang, Z.H. Guo, Y.P. Bai, L. Shao, Recent Advances in Polymeric Solvent-Resistant Nanofiltration Membranes, Adv. Polym. Technol. 33 (2014) E1-E24.

[2] P. Marchetti, M.F. Jimenez Solomon, G. Szekely, A.G. Livingston, Molecular Separation with Organic Solvent Nanofiltration: A Critical Review, Chem. Rev. 114 (2014) 10735-10806.

[3] M.V. Tres, S. Mohr, M.L. Corazza, M. Di Luccio, J.V. Oliveira, Separation of n-butane from soybean oil mixtures using membrane processes, J. Membr. Sci. 333 (2009) 141-146.

[4] M.V. Tres, J.C. Racoski, M. Di Luccio, J.V. Oliveira, H. Treichel, D. de Oliveira, M.A. Mazutti, Separation of soybean oil/n-hexane and soybean oil/n-butane mixtures using ceramic membranes, Food Res. Int. 63, Part A (2014) 33-41.

[5] M.V. Tres, R. Nobrega, R.B. Carvalho, J.V. Oliveira, M.D. Luccio, Solvent recovery from soybean oil/n-hexane mixtures using hollow fiber membrane, Braz. J. Chem. Eng. 29 (2012) 577-584.

[6] N. Stafie, D.F. Stamatialis, M. Wessling, Insight into the transport of hexane-solute systems through tailor-made composite membranes, J. Membr. Sci. 228 (2004) 103-116.

[7] A.P.B. Ribeiro, J.M.L.N. de Moura, L.A.G. Gonçalves, J.C.C. Petrus, L.A. Viotto, Solvent recovery from soybean oil/hexane miscella by polymeric membranes, J. Membr. Sci. 282 (2006) 328-336.

[8] M. Saravanan, B.M. Bhosle, R. Subramanian, Processing hexane-oil miscella using a nonporous polymeric composite membrane, J. Food Eng. 74 (2006) 529-535.

[9] C. Pagliero, N. Ochoa, J. Marchese, M. Mattea, Degumming of crude soybean oil by ultrafiltration using polymeric membranes, J. Am. Oil Chem. Soc. 78 (2001) 793-796.

[10] C. Pagliero, M. Mattea, N. Ochoa, J. Marchese, Fouling of polymeric membranes during degumming of crude sunflower and soybean oil, J. Food Eng. 78 (2007) 194-197.

[11] S. Arora, S. Manjula, A.G.G. Krishna, R. Subramanian, Membrane processing of crude palm oil, Desalination. 191 (2006) 454-466.

[12] A. Koris, G. Vatai, Dry degumming of vegetable oils by membrane filtration, Desalination. 148 (2002) 149-153.

[13] A. García, S. Álvarez, F. Riera, R. Álvarez, J. Coca, Sunflower oil miscella degumming with polyethersulfone membranes: Effect of process conditions and MWCO on fluxes and rejections, J. Food Eng. 74 (2006) 516-522.

[14] L.P. Rama, M. Cheryan, N. Rajagopalan, Solvent recovery and partial deacidification of vegetable oils by membrane technology, Eur. J. Lipid Sci. Technol. 98 (1996) 10-14.

[15] L.P. Raman, M. Cheryan, N. Rajagopalan, Deacidification of soybean oil by membrane technology, J. Am. Oil Chem. Soc. 73 (1996) 219-224.

[16] A. Benazzouz, L. Moity, C. Pierlot, M. Sergent, V. Molinier, J.-M. Aubry, Selection of a Greener Set of Solvents Evenly Spread in the Hansen Space by Space-Filling Design, Ind. Eng. Chem. Res. 52 (2013) 16585-16597.

[17] Z. Li, K.H. Smith, G.W. Stevens, The use of environmentally sustainable bio-derived solvents in solvent extraction applications-A review, Chin. J. Chem. Eng. 24 (2016) 215-220.

[18] F. Chemat, M.A. Vian, eds., Alternative Solvents for Natural Products Extraction, Springer Berlin Heidelberg, Berlin, Heidelberg, 2014.

[19] M. Aqil, A. Ahad, Y. Sultana, A. Ali, Status of terpenes as skin penetration enhancers, Drug Discov. Today. 12 (2007) 1061-1067.

[20] A.C. Williams, B.W. Barry, Essential oils as novel human skin penetration enhancers, Int. J. Pharm. 57 (1989) R7-R9.

[21] L. Caputi, E. Aprea, Use of Terpenoids as Natural Flavouring Compounds in Food Industry, Recent Pat. Food Nutr. Agric. 3 (2011) 9-16.

[22] M. Aissou, Z. Chemat-Djenni, E. Yara-Varón, A.-S. Fabiano-Tixier, F. Chemat, Limonene as an agro-chemical building block for the synthesis and extraction of bioactive compounds, Comptes Rendus Chim. 20 (2017) 346-358. 
[23] M.-T. Golmakani, J.A. Mendiola, K. Rezaei, E. Ibáñez, Pressurized limonene as an alternative biosolvent for the extraction of lipids from marine microorganisms, J. Supercrit. Fluids. 92 (2014) 17.

[24] P.K. Mamidipally, S.X. Liu, First approach on rice bran oil extraction using limonene, Eur. J. Lipid Sci. Technol. 106 (2004) 122-125.

[25] C. Dejoye Tanzi, M. Abert Vian, F. Chemat, New procedure for extraction of algal lipids from wet biomass: a green clean and scalable process, Bioresour. Technol. 134 (2013) 271-275.

[26] C. Dejoye Tanzi, M. Abert Vian, C. Ginies, M. Elmaataoui, F. Chemat, Terpenes as Green Solvents for Extraction of Oil from Microalgae, Molecules. 17 (2012) 8196-8205.

[27] M. Virot, V. Tomao, C. Ginies, F. Chemat, Total Lipid Extraction of Food Using d-Limonene as an Alternative to n-Hexane, Chromatographia. 68 (2008) 311-313.

[28] R. Subramanian, M. Nakajima, T. Kawakatsu, Processing of vegetable oils using polymeric composite membranes, J. Food Eng. 38 (1998) 41-56.

[29] D. Bhanushali, S. Kloos, C. Kurth, D. Bhattacharyya, Performance of solvent-resistant membranes for non-aqueous systems: solvent permeation results and modeling, J. Membr. Sci. 189 (2001) $1-21$.

[30] J. Geens, B. Van der Bruggen, C. Vandecasteele, Transport model for solvent permeation through nanofiltration membranes, Sep. Purif. Technol. 48 (2006) 255-263.

[31] P. Marchetti, A. Butté, A.G. Livingston, An improved phenomenological model for prediction of solvent permeation through ceramic NF and UF membranes, J. Membr. Sci. 415-416 (2012) 444458.

[32] Y. Zhao, Q. Yuan, Effect of membrane pretreatment on performance of solvent resistant nanofiltration membranes in methanol solutions, J. Membr. Sci. 280 (2006) 195-201.

[33] J.P. Robinson, E.S. Tarleton, C.R. Millington, A. Nijmeijer, Solvent flux through dense polymeric nanofiltration membranes, J. Membr. Sci. 230 (2004) 29-37.

[34] P. Silva, S. Han, A.G. Livingston, Solvent transport in organic solvent nanofiltration membranes, J. Membr. Sci. 262 (2005) 49-59.

[35] S. Darvishmanesh, A. Buekenhoudt, J. Degrève, B. Van der Bruggen, General model for prediction of solvent permeation through organic and inorganic solvent resistant nanofiltration membranes, J. Membr. Sci. 334 (2009) 43-49.

[36] S. Darvishmanesh, A. Buekenhoudt, J. Degrève, B. Van der Bruggen, Coupled series-parallel resistance model for transport of solvent through inorganic nanofiltration membranes, Sep. Purif. Technol. 70 (2009) 46-52.

[37] P. Marchetti, A.G. Livingston, Predictive membrane transport models for Organic Solvent Nanofiltration: How complex do we need to be?, J. Membr. Sci. 476 (2015) 530-553.

[38] D.R. Paul, O.M. Ebra-Lima, Pressure-induced diffusion of organic liquids through highly swollen polymer membranes, J. Appl. Polym. Sci. 14 (1970) 2201-2224.

[39] J.G. Wijmans, R.W. Baker, The solution-diffusion model: a review, J. Membr. Sci. 107 (1995) 121.

[40] D.R. Paul, DIFFUSIVE TRANSPORT IN SWOLLEN POlYMER MEMBRANES., Am. Chem. Soc. Div. Org. Coat. Plast. Chem. Prepr. 34 (1974) 436-441.

[41] M. Mulder, Basic Principles of Membrane Technology, Springer Science \& Business Media, 1996.

[42] H.T. Lu, S. Kanehashi, C.A. Scholes, S.E. Kentish, The potential for use of cellulose triacetate membranes in post combustion capture, Int. J. Greenh. Gas Control. 55 (2016) 97-104.

[43] X. Duthie, S. Kentish, C. Powell, K. Nagai, G. Qiao, G. Stevens, Operating temperature effects on the plasticization of polyimide gas separation membranes, J. Membr. Sci. 294 (2007) 40-49.

[44] F. Banihashemi, M. Pakizeh, A. Ahmadpour, CO2 separation using PDMS/ZSM-5 zeolite composite membrane, Sep. Purif. Technol. 79 (2011) 293-302.

[45] T.C. Merkel, V.I. Bondar, K. Nagai, B.D. Freeman, I. Pinnau, Gas sorption, diffusion, and permeation in poly(dimethylsiloxane), J. Polym. Sci. Part B Polym. Phys. 38 (2000) 415-434. 
[46] S. Li, F. Qin, P. Qin, M.N. Karim, T. Tan, Preparation of PDMS membrane using water as solvent for pervaporation separation of butanol-water mixture, Green Chem. 15 (2013) 2180-2190.

[47] S. Salehi Shahrabi, H.R. Mortaheb, J. Barzin, M.R. Ehsani, Pervaporative performance of a PDMS/blended PES composite membrane for removal of toluene from water, Desalination. 287 (2012) 281-289.

[48] S.V. Dixon-Garrett, K. Nagai, B.D. Freeman, Ethylbenzene solubility, diffusivity, and permeability in poly(dimethylsiloxane), J. Polym. Sci. Part B Polym. Phys. 38 (2000) 1461-1473.

[49] H.-K. Oh, K.-H. Song, K.-R. Lee, J.-M. Rim, Prediction of sorption and flux of solvents through PDMS membrane, Polymer. 42 (2001) 6305-6312.

[50] J. Crank, The Mathematics of Diffusion, Clarendon Press, 1979.

[51] H. Ben Soltane, D. Roizard, E. Favre, Effect of pressure on the swelling and fluxes of dense PDMS membranes in nanofiltration: An experimental study, J. Membr. Sci. 435 (2013) 110-119.

[52] C.M. Hansen, Hansen Solubility Parameters: A User's Handbook, Second Edition, CRC Press, 2007.

[53] A. Filly, A.-S. Fabiano-Tixier, Y. Lemasson, C. Roy, X. Fernandez, F. Chemat, Extraction of aroma compounds in blackcurrant buds by alternative solvents: Theoretical and experimental solubility study, Comptes Rendus Chim. 17 (2014) 1268-1275.

[54] D.R. Paul, O.M. Ebra-Lima, The mechanism of liquid transport through swollen polymer membranes, J. Appl. Polym. Sci. 15 (1971) 2199-2210.

[55] D.R. Machado, D. Hasson, R. Semiat, Effect of solvent properties on permeate flow through nanofiltration membranes. Part I: investigation of parameters affecting solvent flux, J. Membr. Sci. 163 (1999) 93-102.

[56] P. Vandezande, L.E.M. Gevers, I.F.J. Vankelecom, Solvent resistant nanofiltration: separating on a molecular level, Chem. Soc. Rev. 37 (2008) 365-405.

[57] R.D. Raharjo, B.D. Freeman, E.S. Sanders, Pure and mixed gas $\mathrm{CH} 4$ and $\mathrm{n}-\mathrm{C} 4 \mathrm{H} 10$ sorption and dilation in poly(dimethylsiloxane), J. Membr. Sci. 292 (2007) 45-61.

[58] R.D. Raharjo, B.D. Freeman, D.R. Paul, G.C. Sarti, E.S. Sanders, Pure and mixed gas CH4 and nC4H10 permeability and diffusivity in poly(dimethylsiloxane), J. Membr. Sci. 306 (2007) 75-92. 


\title{
SUPPLEMENTARY INFORMATION
}

\section{Transport of terpenes through composite PDMS/PAN solvent resistant nanofiltration membranes}

\author{
M. H. Abdellah, C. A. Scholes ${ }^{a}$, B. D. Freeman ${ }^{\text {, }}$ L. Liü, S. E. Kentish* \\ ${ }^{a}$ Department of Chemical Engineering, The University of Melbourne, Parkville, Melbourne, \\ 3010, Australia \\ ${ }^{b}$ Department of Chemical Engineering, The University of Texas at Austin, Austin, Texas \\ 78712, United States
}

\section{Atomic Force Microscopy (AFM)}

AFM measurements were carried out in AC mode in air ambient using Cypher AFM (Asylum, US). The cantilever used was Tap-300 from Budget Sensors, which has a resonance frequency of $300 \mathrm{kHz}$ and a spring constant of $40 \mathrm{~N} / \mathrm{m}$. The scan size and the scan rate were set as $5 \mathrm{um}$ and $1 \mathrm{~Hz}$. The images were processed by Igor Pro 6.

A)

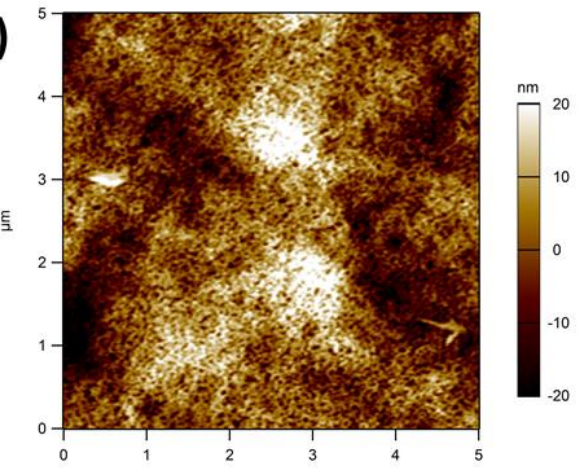

C)

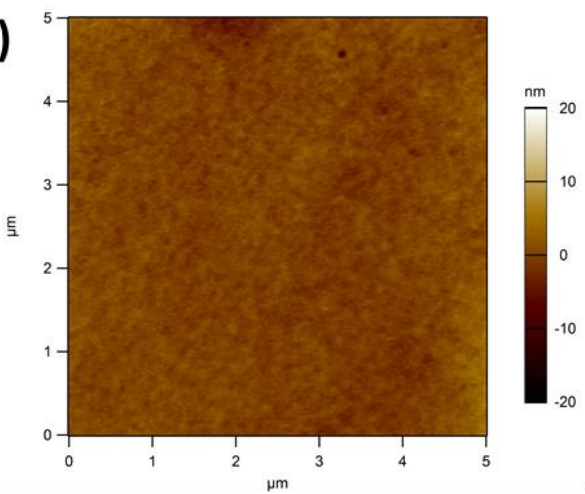

B)

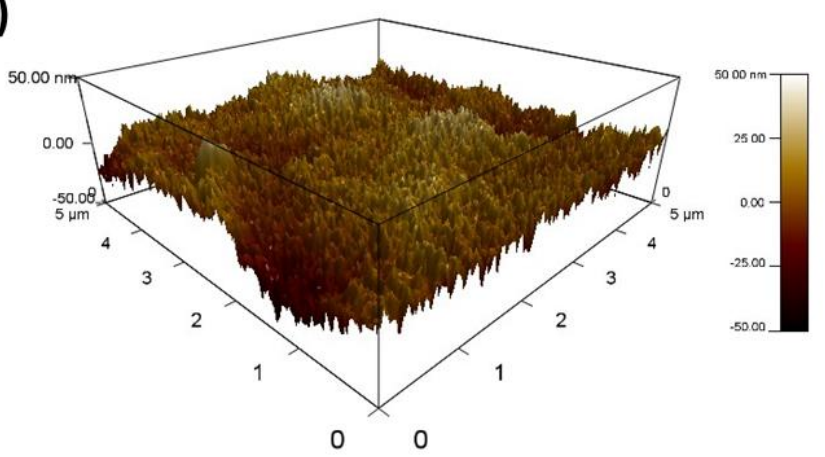

D)
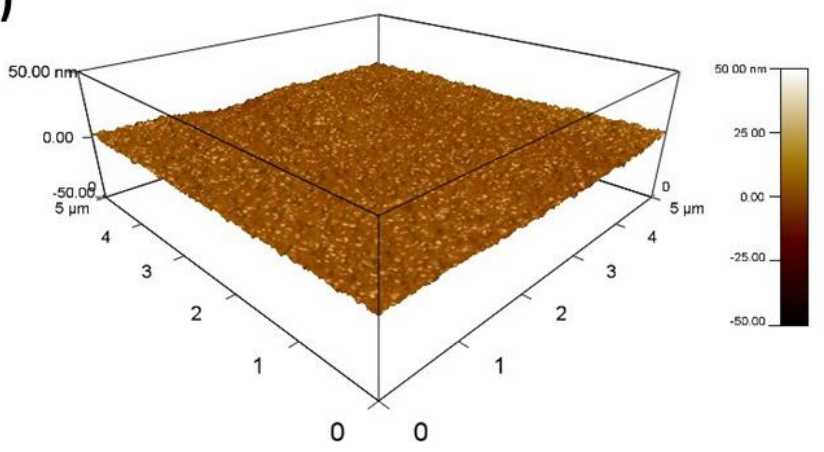

Figure S1. AFN 2D/3D images of PAN support membrane (A, B) and PDMS/PAN composite membrane (C,D) 


\section{Contact Angle Measurement}

The contact angle of both the PAN support and PDMS/PAN thin film composite membrane was determined using a First Ten Angstroms FTA200 Tensiometer.

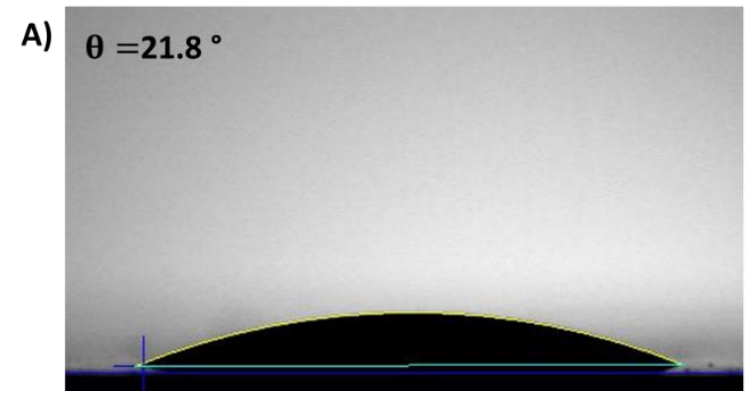

B) $\theta=114.7^{\circ}$

Figure S2. Water contact angle of A) PAN support membrane and B) PDMS/PAN TFC membrane 